\title{
Probabilistic assessment of port operation downtimes under climate change
}

\section{P. Camus}

camusp@unican.es

\section{A. Tomás}

G. Díaz-Hernández

B. Rodríguez

C. Izaguirre

I.J. Losada

Environmental Hydraulics Institute, Universidad de Cantabria - Avda. Isabel Torres, 15, Parque Científico y Tecnológico de Cantabria, 39011, Santander, Spain

${ }^{*}$ Corresponding author.

Abstract

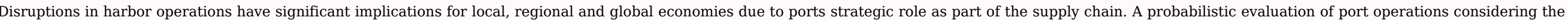

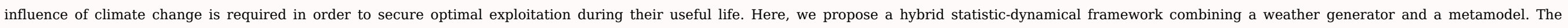

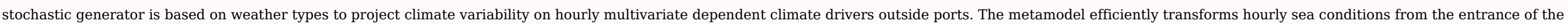

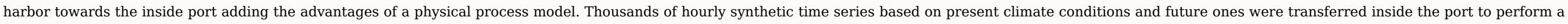

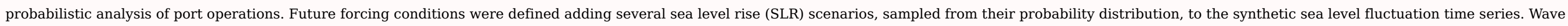

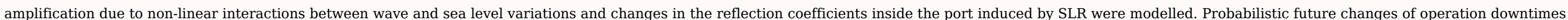

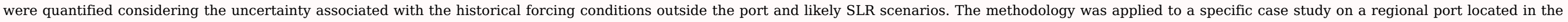
north coast of Spain, were port operability due to wave agitation was assessed.

\section{Introduction}

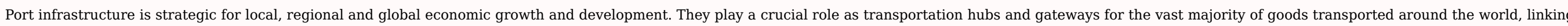

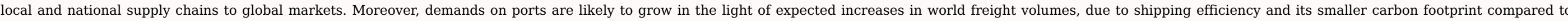

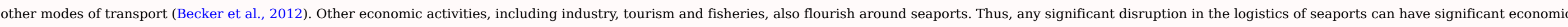

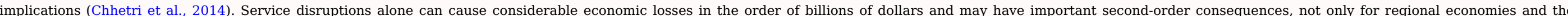
quality of life of those who depend directly on the port's functionality, but also for the operation of global supply-chains (Becker et al., 2013).

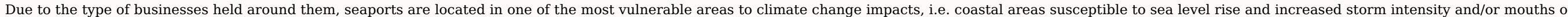

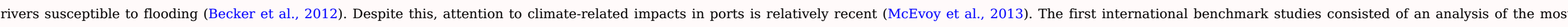

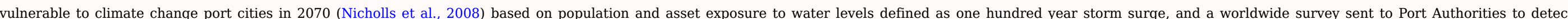
sectorial perceptions regarding port risks due to climate change (Becker et al., 2012), respectively.

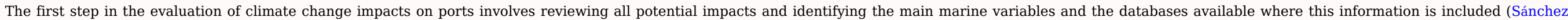




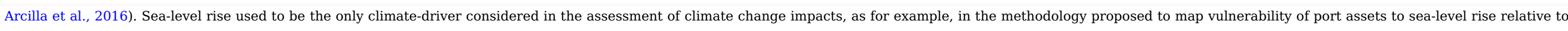

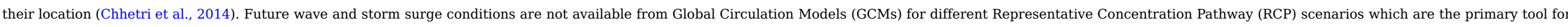

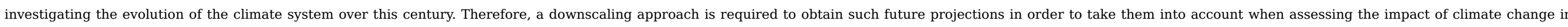

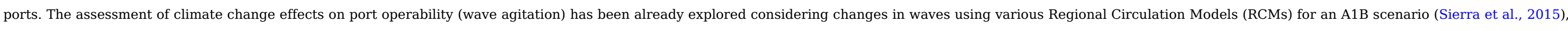

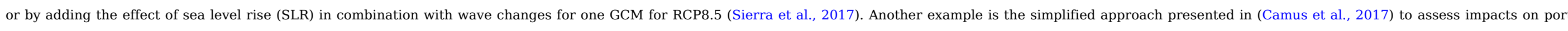

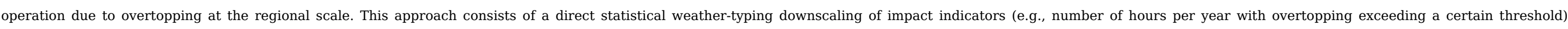

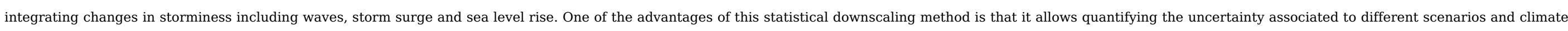
models (30 GCMs for 2 RCPs were projected), which is not possible if only one or a limited number of GCMs or RCMs are considered.

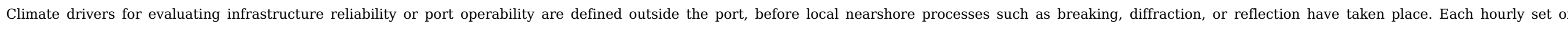

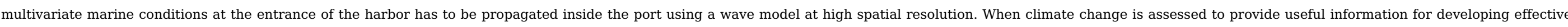

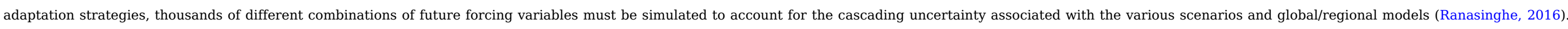

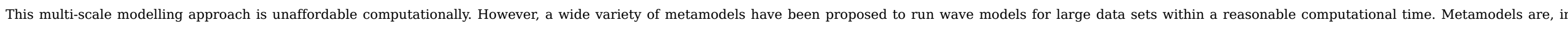

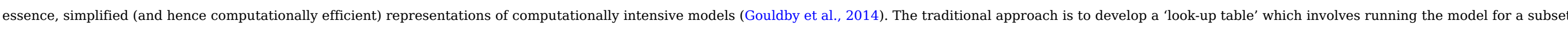

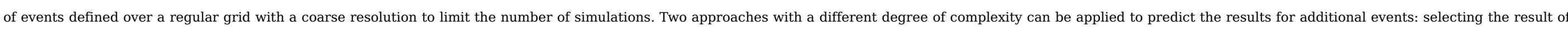

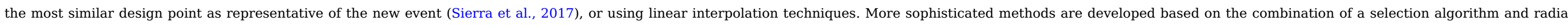

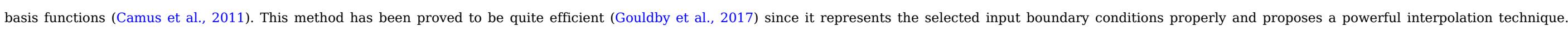

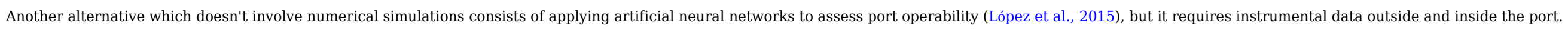

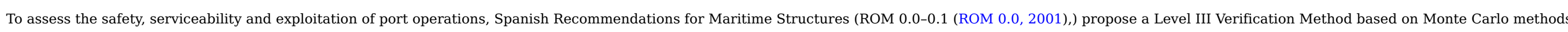

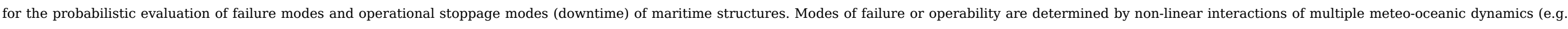

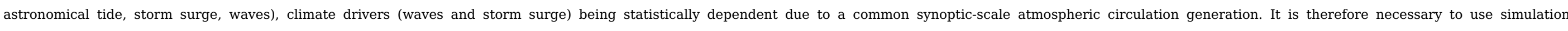

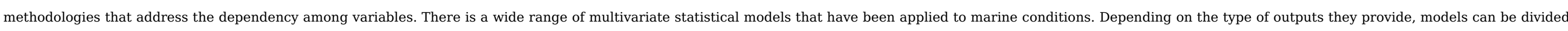

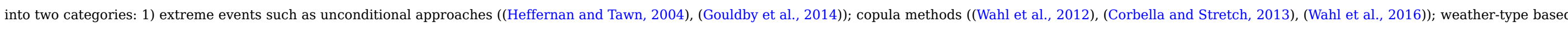

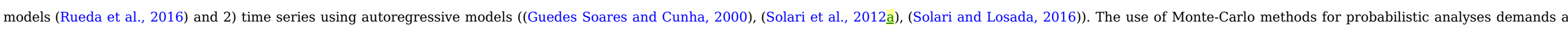
high computational effort to assess infrastructure failure modes or port operability. The process is even more complex if the probabilistic verification is also performed including climate change projections.

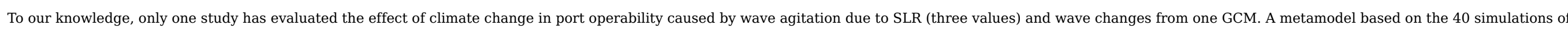

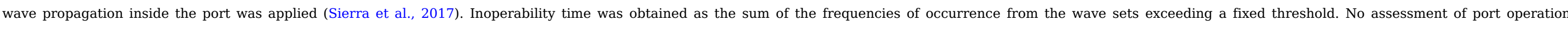
downtimes due to wave agitation has been performed using a Monte-Carlo approach, nor including climate change.

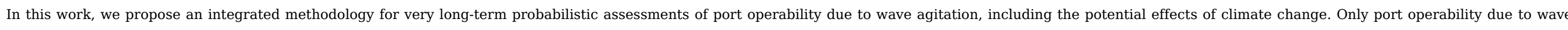

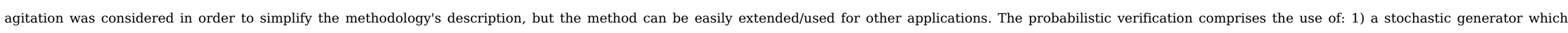

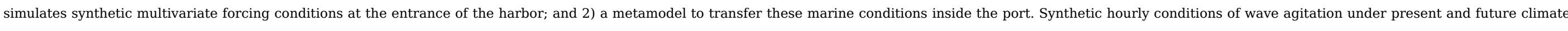

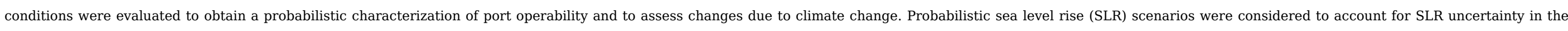
evaluation of future operation downtimes. The application of the methodology was particularized to a regional fishing port currently experiencing recurrent downtimes.

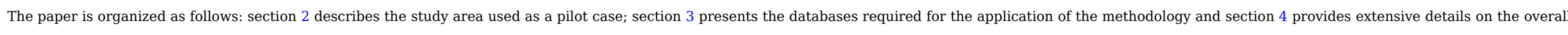

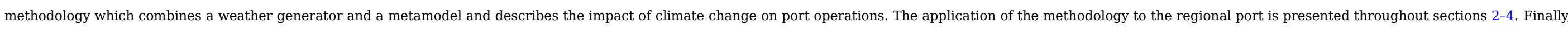
section 5 summarizes and concludes the work.

\section{Study area}




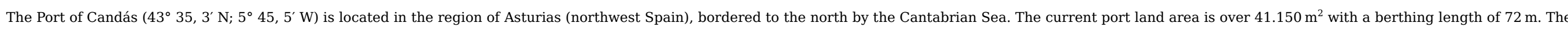

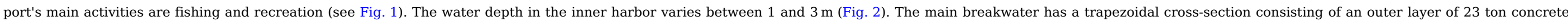

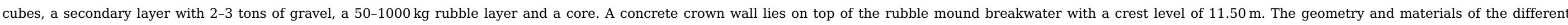

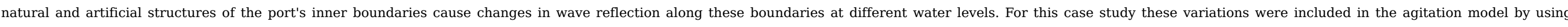

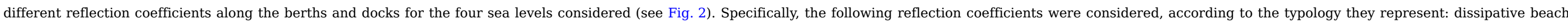
$(\mathrm{Kr}=0.15)$, reflecting beach $(\mathrm{Kr}=0.20)$, rubble-mound breakwater $(\mathrm{Kr}=0.40)$, cliff $(\mathrm{Kr}=0.60)$ and vertical wharf $(\mathrm{Kr}=0.9)$. For low and mean tide reflection coefficients were kept constant.

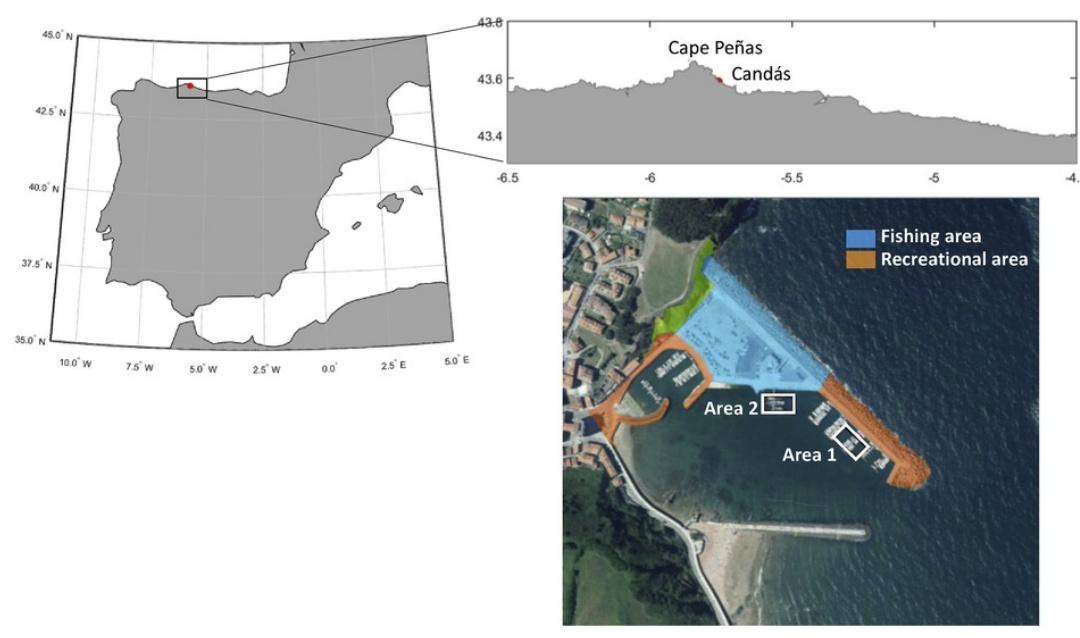

Fig. 1 Location of the Port of Candás in northern Spain. 


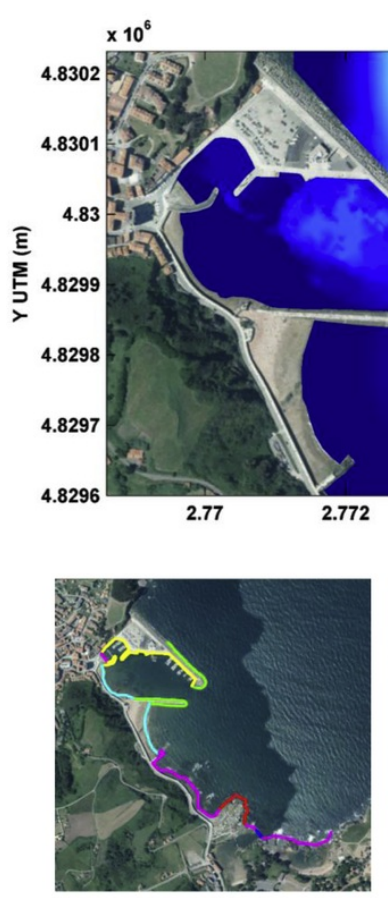

Low and mean tide

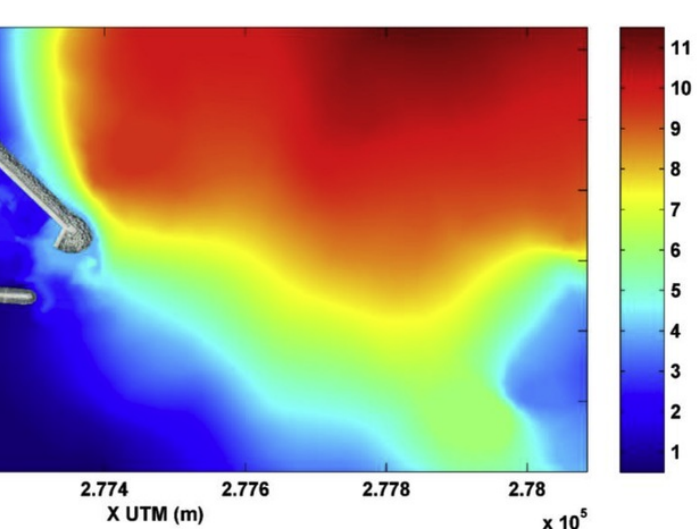

$\times 10^{5}$

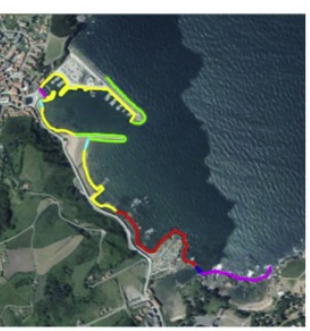

High tide

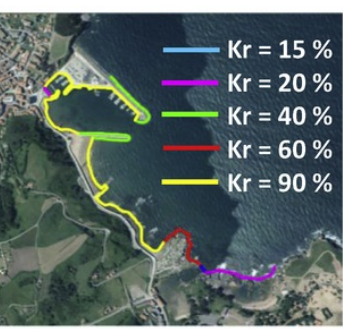

High tide + SLR

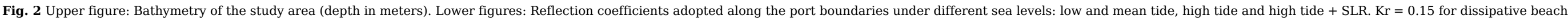
$\mathrm{Kr}=0.20$ for reflecting beach, $\mathrm{Kr}=0.40$ for rubble-mound breakwater, $\mathrm{Kr}=0.60$ for cliff and $\mathrm{Kr}=0.9$ for vertical wharf.

alt-text: Fig. 2

\section{Databases}

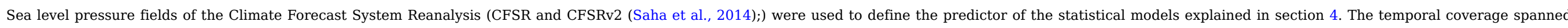
from 1979 to 2013, with an hourly temporal resolution and a $0.5^{\circ}$ spatial resolution.

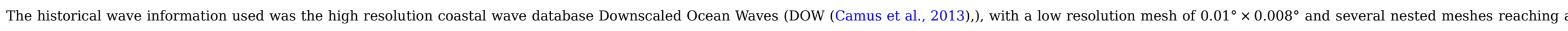

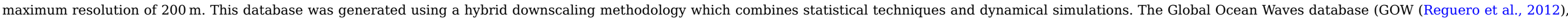

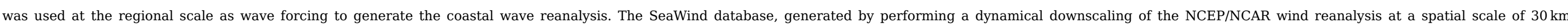

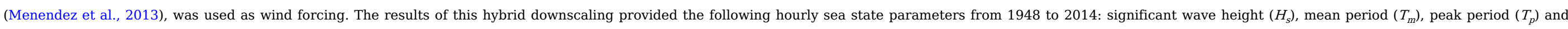
wave direction ( $\boldsymbol{\theta}$ ).

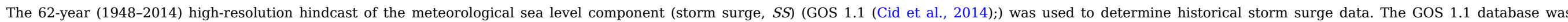
developed for Southern Europe using the Regional Ocean Model System (ROMS) with a horizontal resolution of $1 / 8^{\circ}(\sim 14 \mathrm{~km})$.

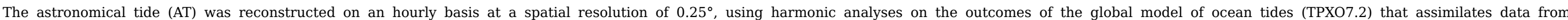
TOPEX/Poseidon missions and tidal gauges for the common period of waves and storm surge.

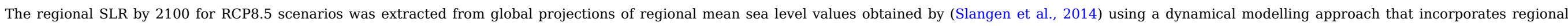
contributions of land ice, groundwater depletion and glacial isostatic adjustment, including gravitational effects due to mass redistribution. 


\section{Methodology and results}

The methodology described in Fig. 3 is composed of two main parts:

- A weather generator to derive hourly multivariate marine conditions outside the port.

- A metamodel to transfer hourly marine conditions outside the port as generated in the previous step to the inner harbor, in order to obtain wave agitation.

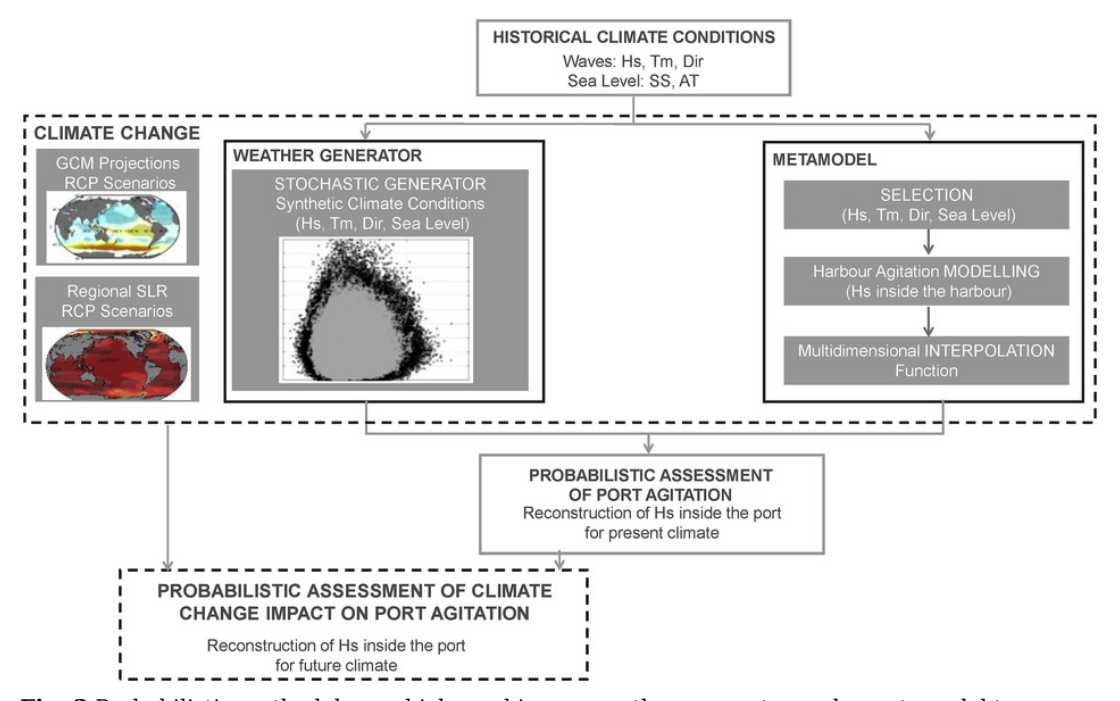

Fig. 3 Probabilistic methodology which combines a weather generator and a metamodel to assess port operability due to wave agitation under present and future conditions. alt-text: Fig. 3

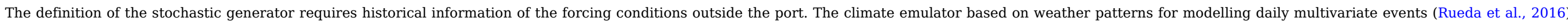

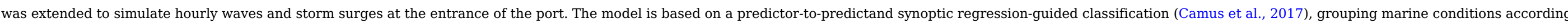

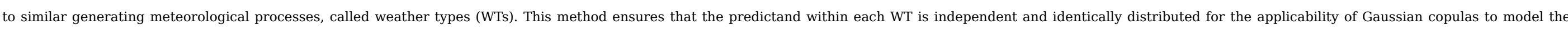

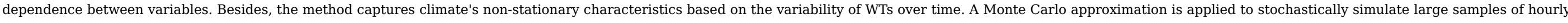
conditions at the entrance of the harbor.

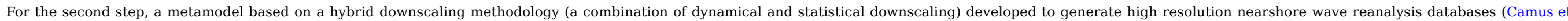

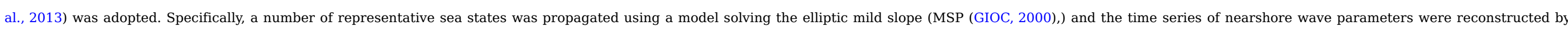

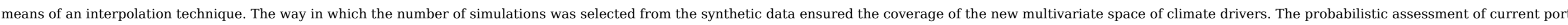
operability due to wave agitation was obtained by reconstructing the significant wave height inside the port for each simulated hourly condition at the entrance of the harbor for the present climate.

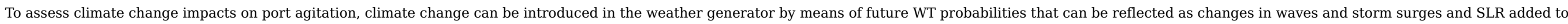

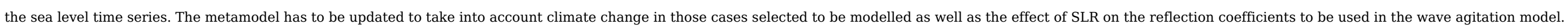

Fig. 4 shows the time series for years 2013 and 2014 and the distribution of $H_{s}$

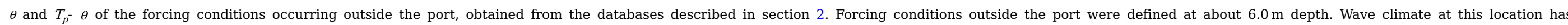

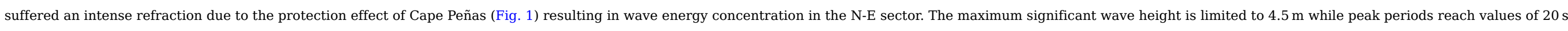
which can be combined with storm surges of almost $0.5 \mathrm{~m}$ and high spring tides over $2.0 \mathrm{~m}$. 

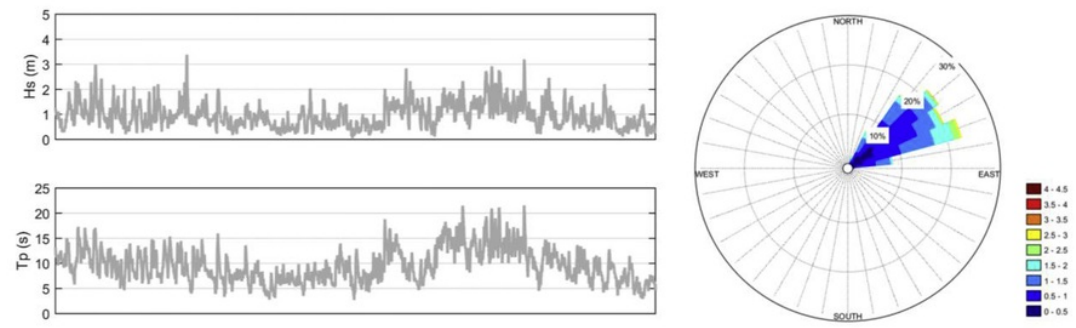

E.5.
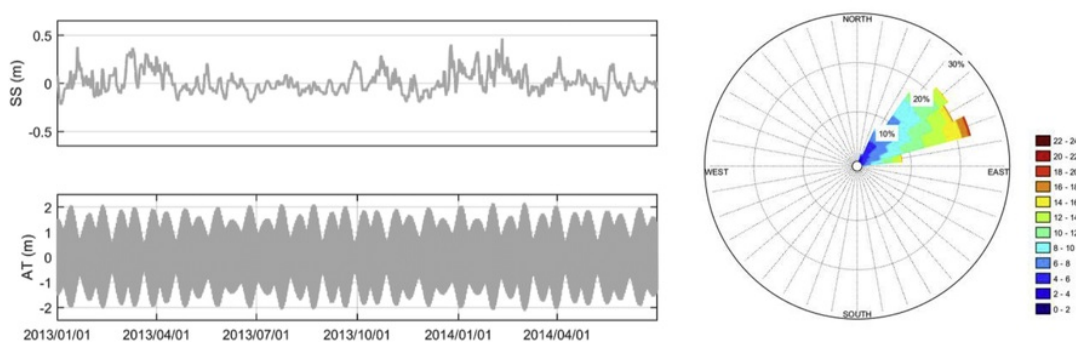

Fig. $4 H_{S^{\prime}} T_{p}$, SS and $A T$ values for two years within the time series) at the entrance of the harbor (left panels). $H_{S}$ and $T_{p}$ roses (right panels).

\section{alt-text: Fig. 4}

\subsection{Weather generator}

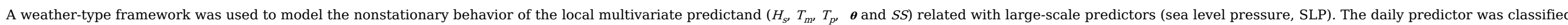

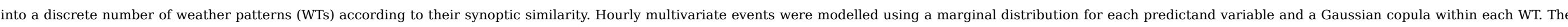

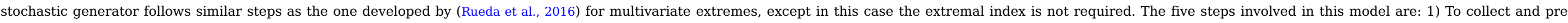

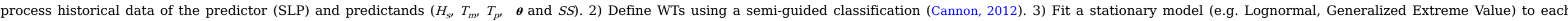

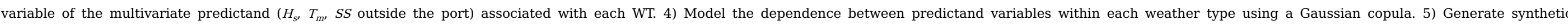
multivariate hourly conditions taking into account the monthly WT probability and dependence structure associated with each WT.

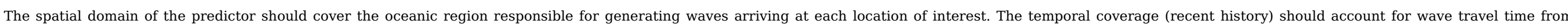

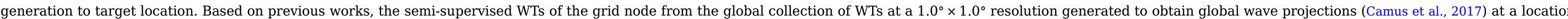

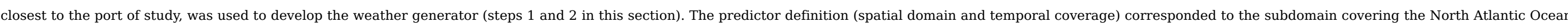

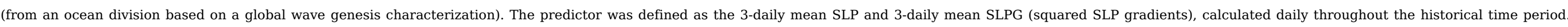

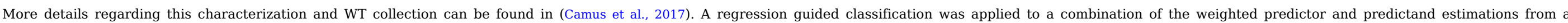

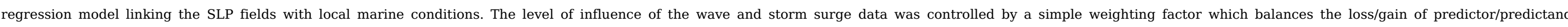

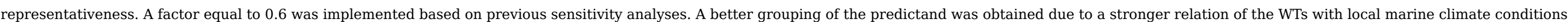

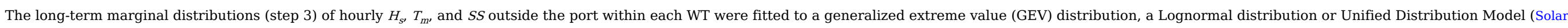

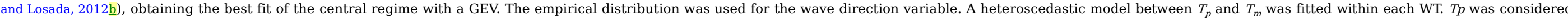

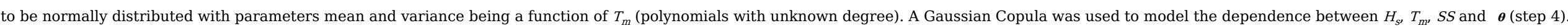

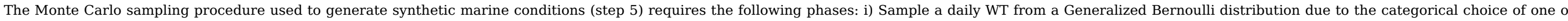

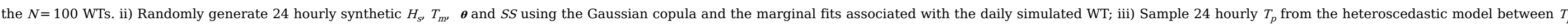

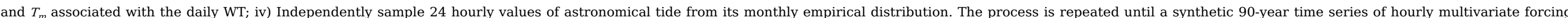




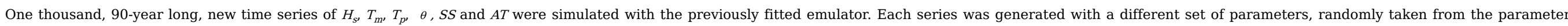

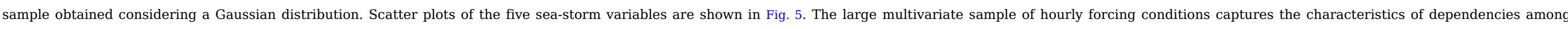

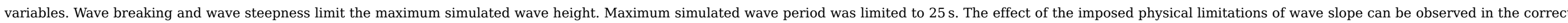

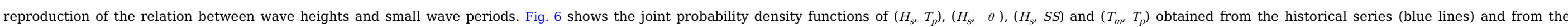

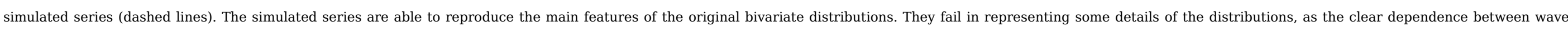
heights around $1.0 \mathrm{~m}$ and low peak periods.

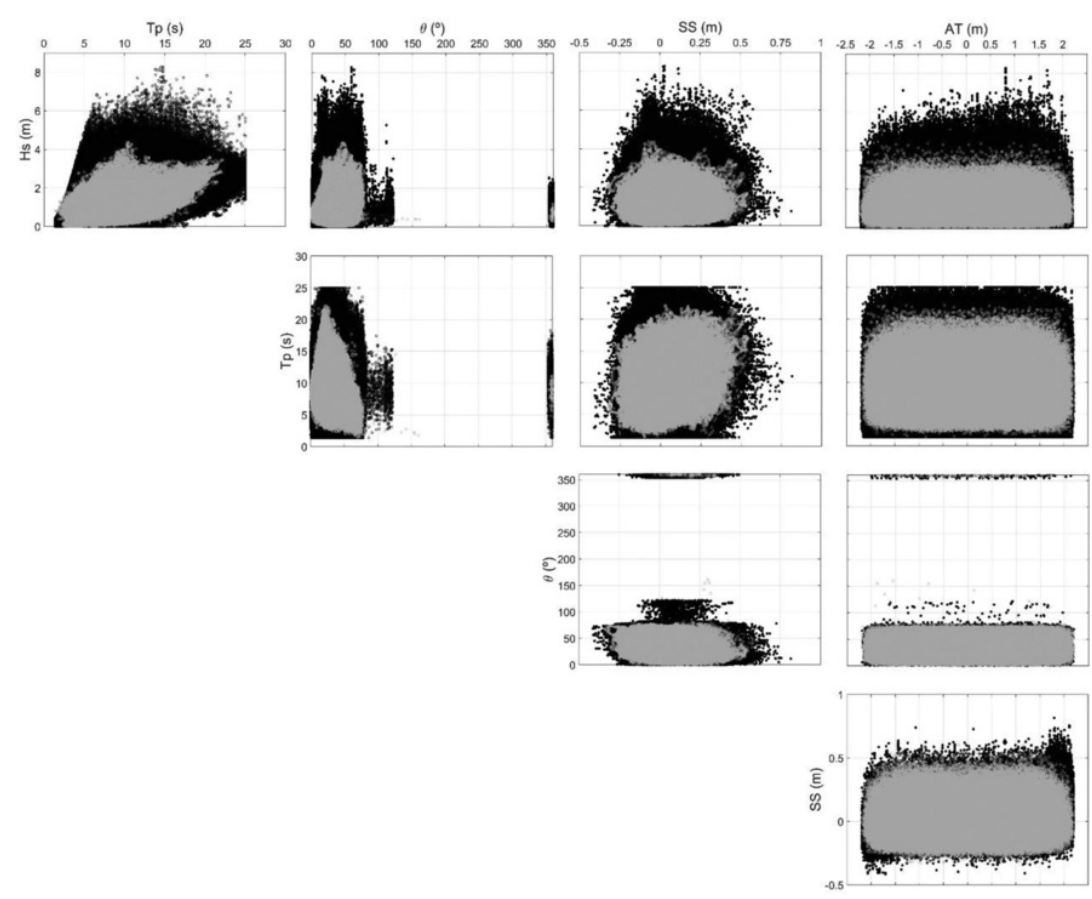

Fig. 5 Scatter plots of marine climate $\left(H_{S^{\prime}} T_{p}, \boldsymbol{\theta}, S S, A T\right)$ at the entrance of the port. Historical data: grey dots; Monte Carlo simulations (1000 samples of 50 years of hourly data): black dots. alt-text: Fig. 5 

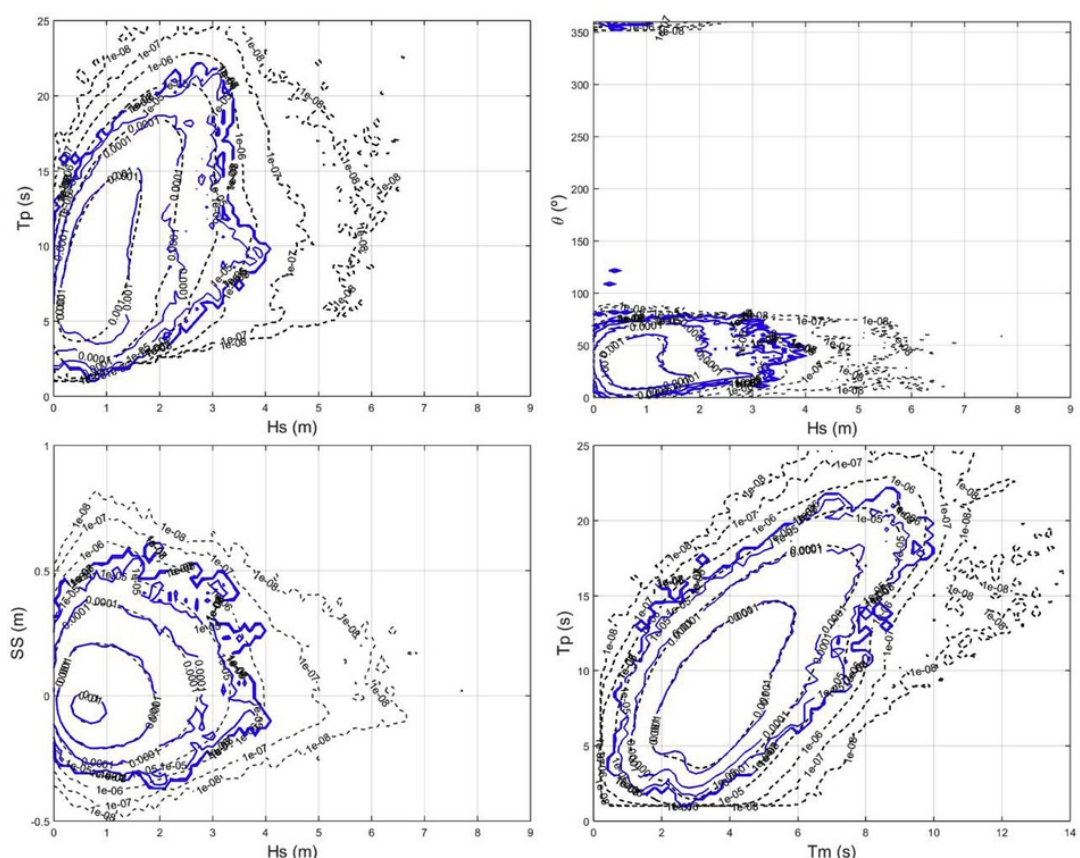

Simulations ( $1000 \times 50$ years)

Observations (1000x50 years)

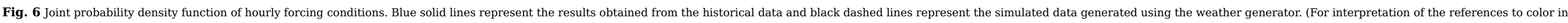
this figure legend, the reader is referred to the Web version of this article.)

\section{alt-text: Fig. 6}

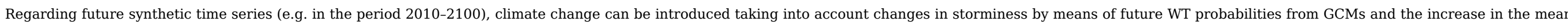

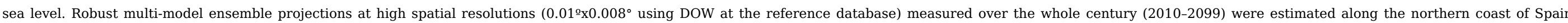

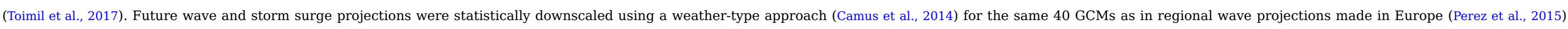

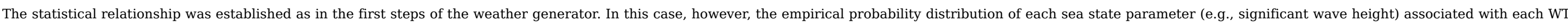

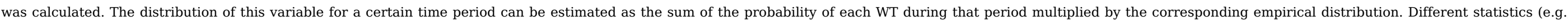

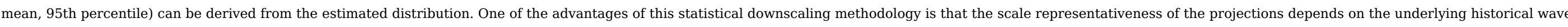

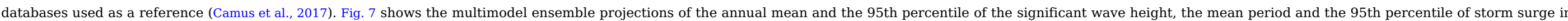

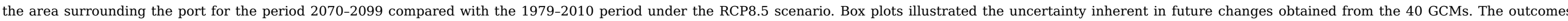

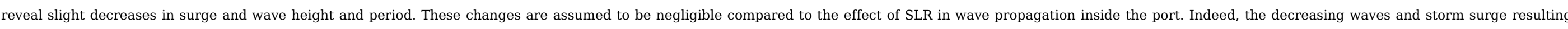
from these expected changes would underestimate the need for port operation downtimes. 

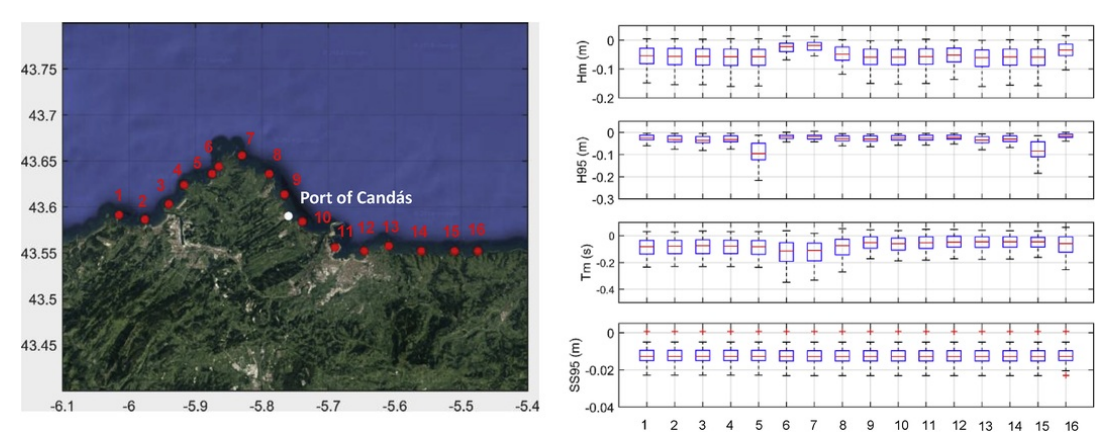

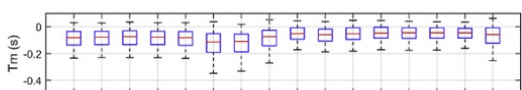

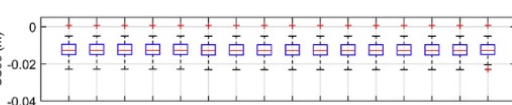

alt-text: Fig. 7

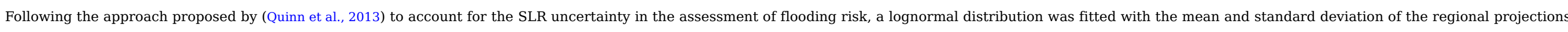

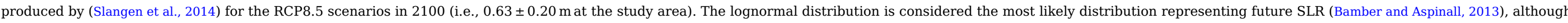

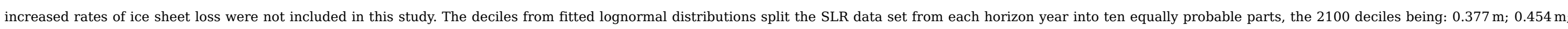

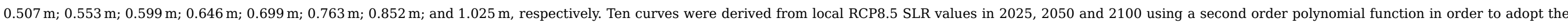

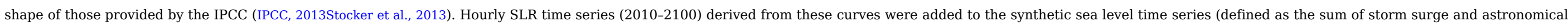
tide) to define future forcing conditions of port agitation.

\subsection{Metamodel}

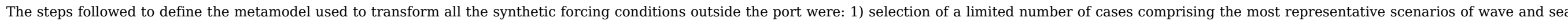

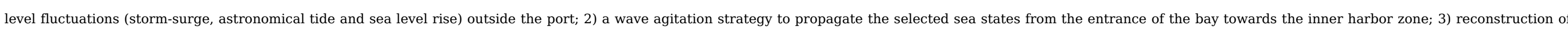
the time series of significant wave heights inside the port.

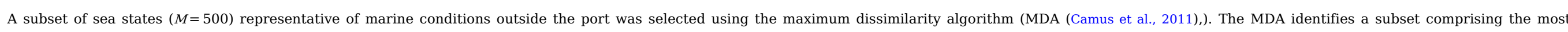

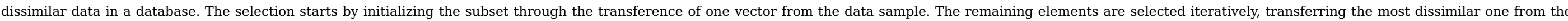

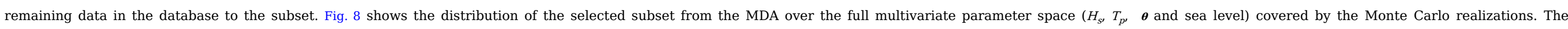

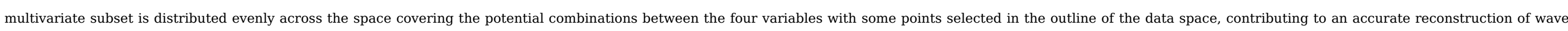
agitation conditions inside the port using the proposed metamodel. 

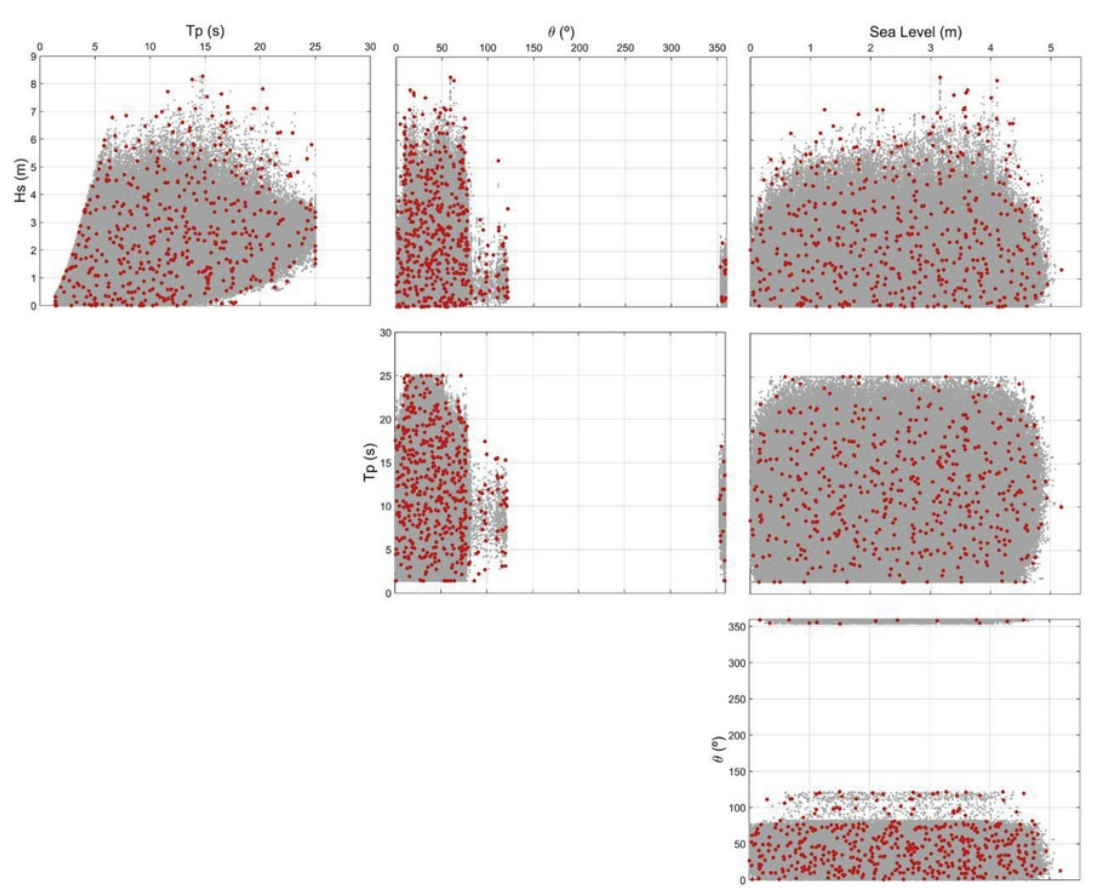

Fig. 8 Scatter plots of simulated data (grey dots) and the selected cases using the MDA (red dots in). (For interpretation of the references to color in this figure legend, the reader is referred to the Web version of this article.) alt-text: Fig. 8

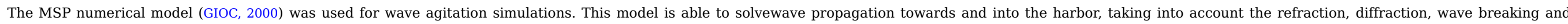

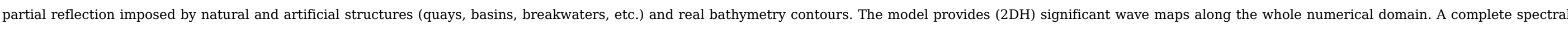

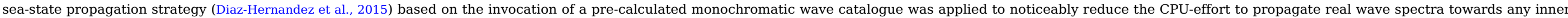
control point. This technique is based on a three-step method:

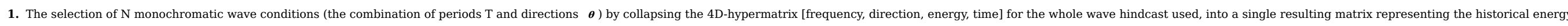

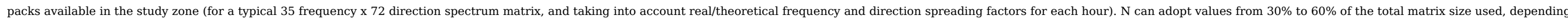
on the geographical location of the harbor/outer wave climate.

2. The numerical propagation of each $\mathrm{N}$ monochromatic wave (using a constant wave height $\mathrm{H}$, because of the linear nature of the model used) and for the different sea levels considered.

3. The aggregation of any spectrum by adding all the individual energy packs that define it.

For this study additional considerations were established:

4. Four water levels were used (total Nx4 monochromatic cases) (three to cover the astronomical tide range and one as expected upper SLR).

5. Changes in reflection coefficients in the model's setup (as described in the study area section) due to SLR.

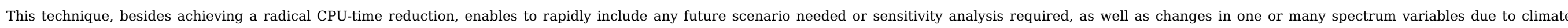

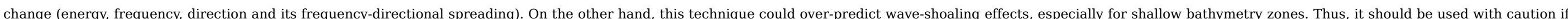




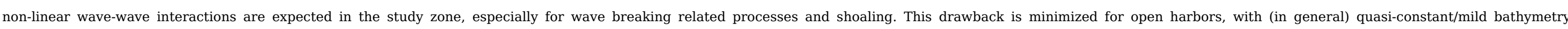

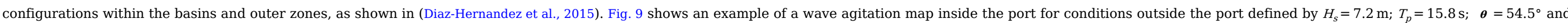
sea level $=3.63 \mathrm{~m}$.

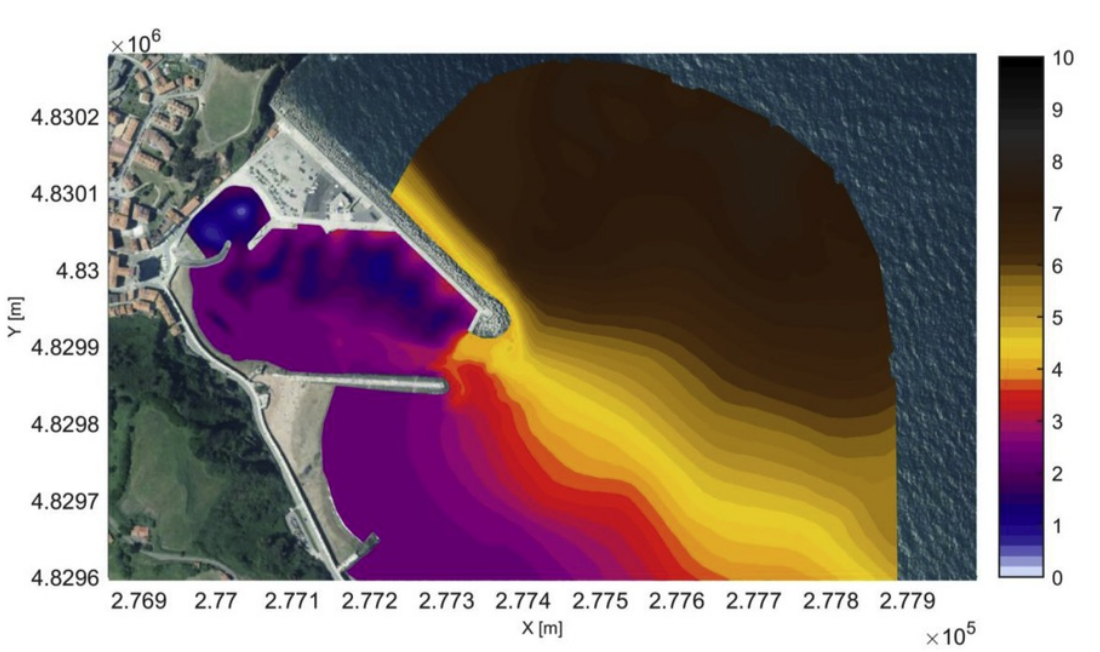

Fig. 9 Wave agitation map for the following marine conditions outside the port: $H_{S}=7.2 \mathrm{~m} ; T_{p}=15.8 \mathrm{~s} ; \boldsymbol{\theta}=54.5^{\circ}$ and sea level $=3.63 \mathrm{~m}$

alt-text: Fig. 9

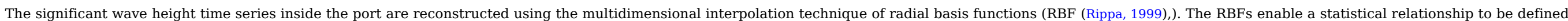

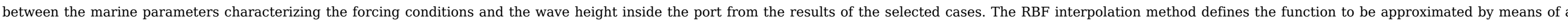

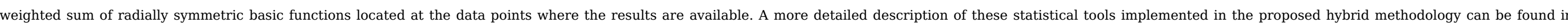
(Camus et al., 2011).

\subsection{Results}

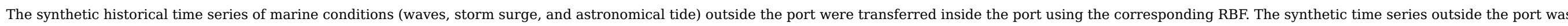
transformed to the future period 2010-2099 adding the corresponding SLR to each hourly sea level. Their corresponding wave height inside the port was reconstructed applying the RBF.

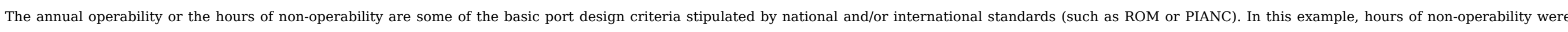

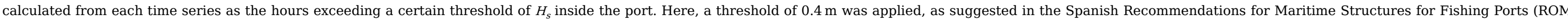
3.1-99 (ROM 3.1, 1999),).

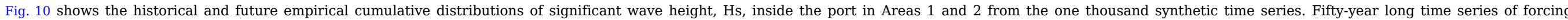

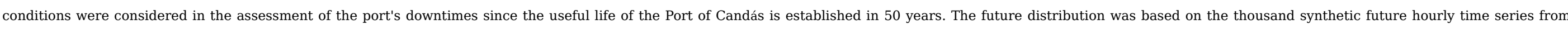

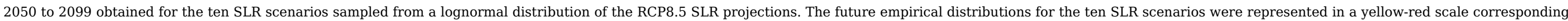

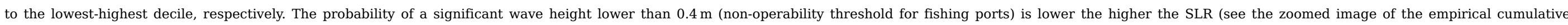
distribution between 0.35 and $0.45 \mathrm{~m}$ in Fig. 10). 

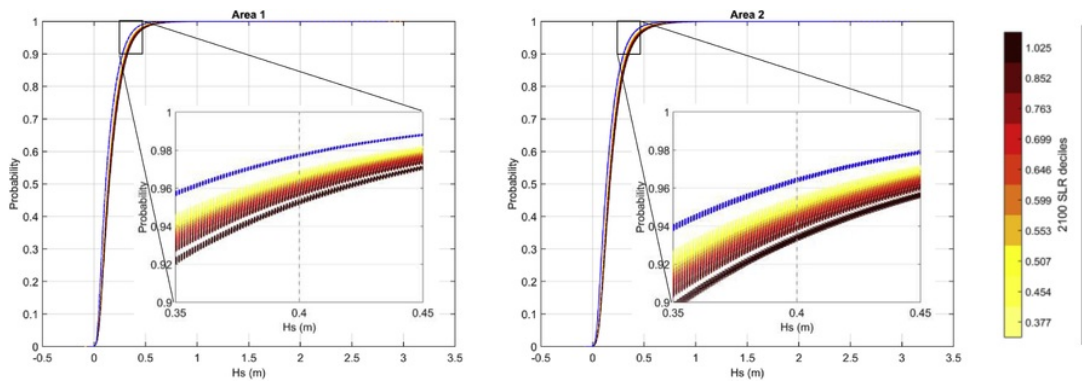

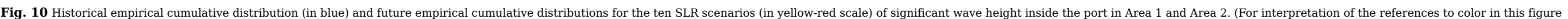
legend, the reader is referred to the Web version of this article.)

\section{alt-text: Fig. 10}

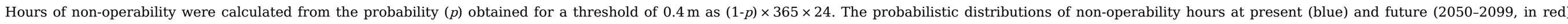

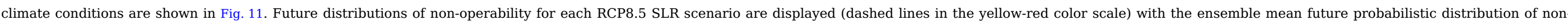

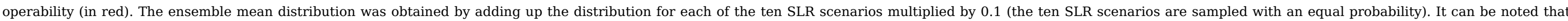
hours of non-operability do increase from present to future conditions for both areas.
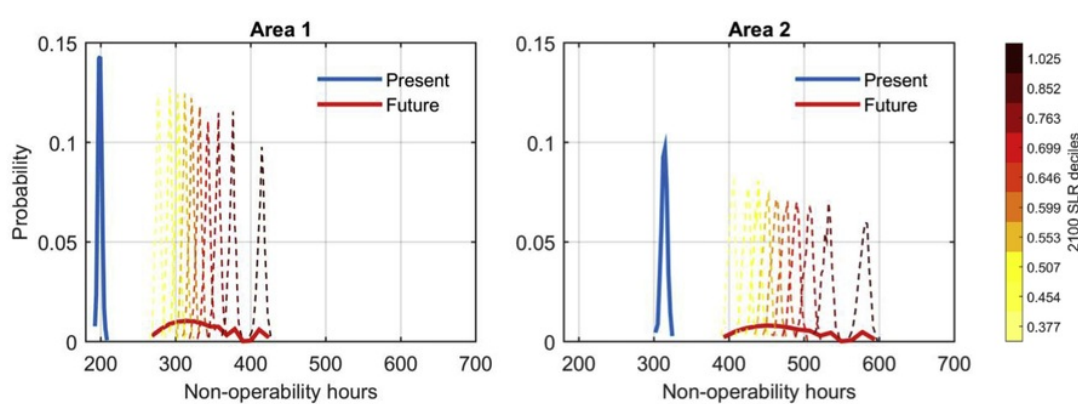

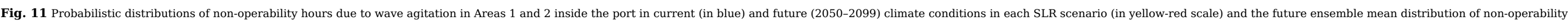
hours (thick red line). (For interpretation of the references to color in this figure legend, the reader is referred to the Web version of this article.)

\section{alt-text: Fig. 11}

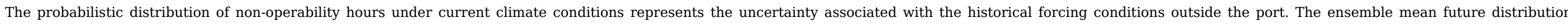

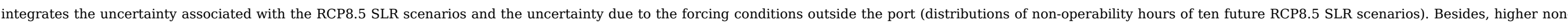
operability hours, as well as a higher uncertainty, are expected for higher SLR scenarios, as can be observed in wider probabilistic distributions of non-operability hours the higher the SLR decile (see Fig. 11).

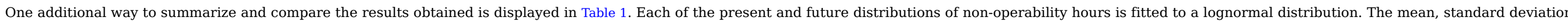

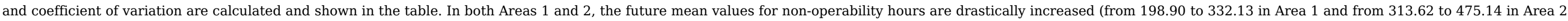

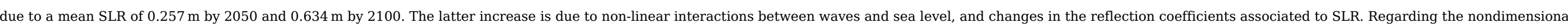

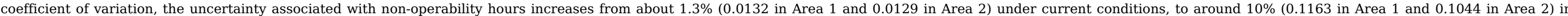

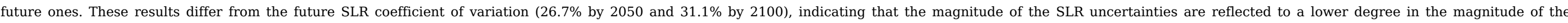
uncertainty of non-operability hours.

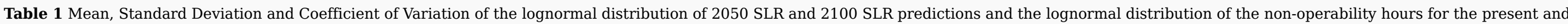


RCP8.5 SLR (m)

RCP8.5 SLR (m)

\begin{tabular}{|l|l|}
\hline Mean & 0.2 \\
\hline Std & 0.069 \\
\hline CV (std/mean) & 0.267 \\
\hline
\end{tabular}

\section{0}

\section{0}

\section{(}

CV (std/mean)

0.634

0.257
0.069
0.267

0.197

0.311

\begin{tabular}{|l|l|}
\multicolumn{1}{|c|}{ Present } & \\
\hline 198.90 & 332.13 \\
\hline 2.625 & 38.61 \\
\hline 0.0132 & 0.1163 \\
\hline
\end{tabular}

\section{Area 1}

Non-operability (hours)

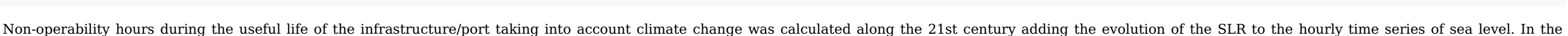

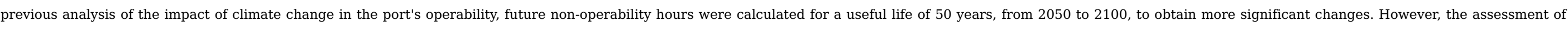

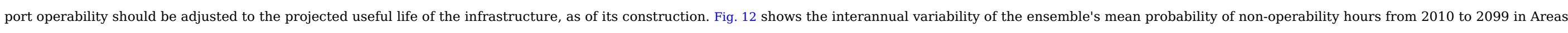

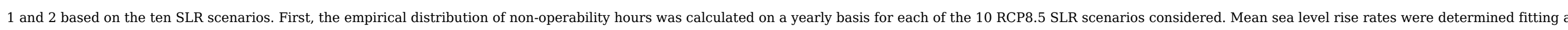

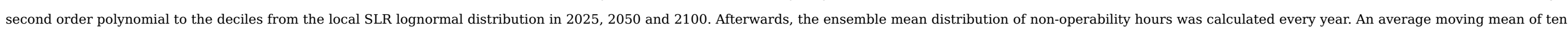

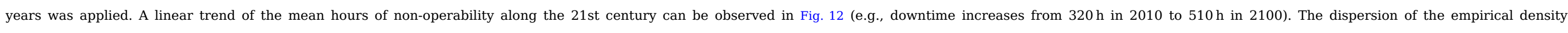

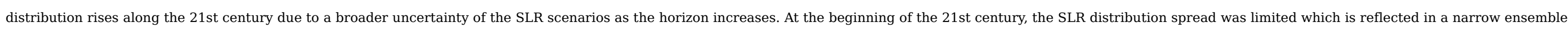

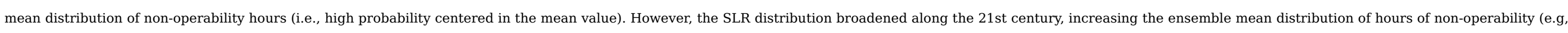

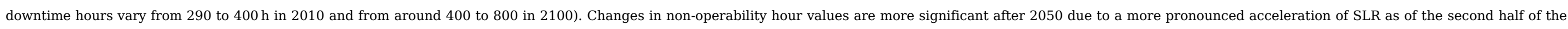
21st century.
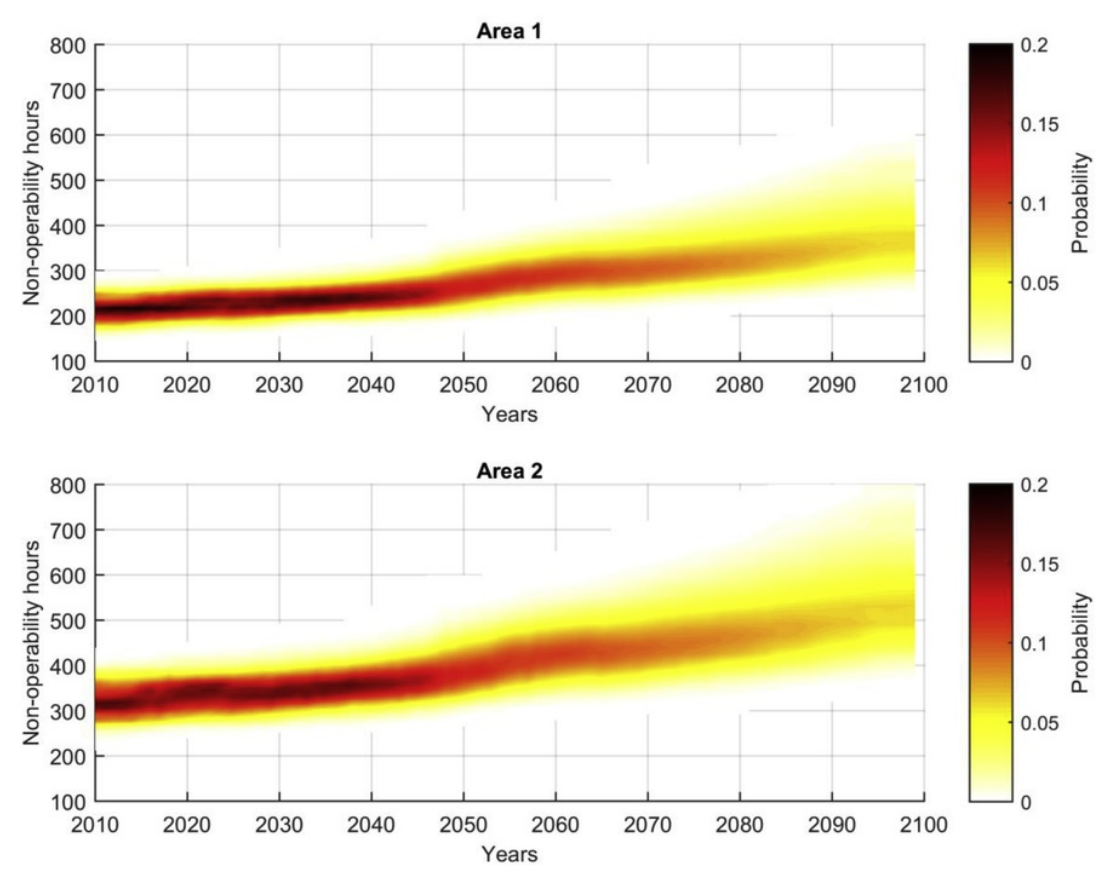


\section{alt-text: Fig. 12}

\section{Summary and conclusions}

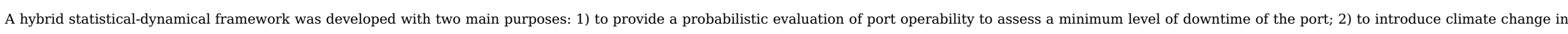
the assessment of port operability during its useful life.

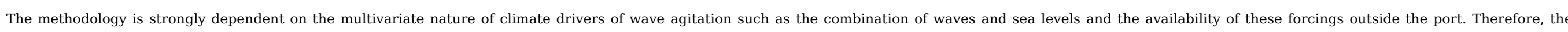

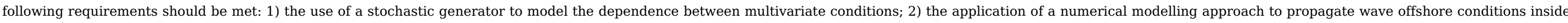
the port.

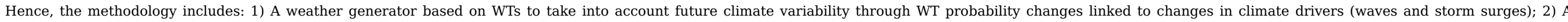

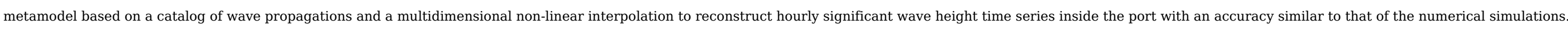

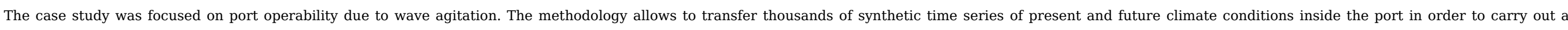

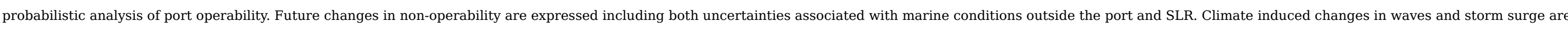

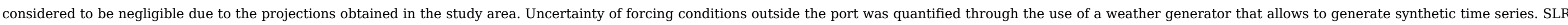

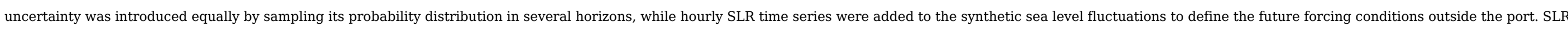
uncertainty was integrated in the future non-operability evaluation joining the contribution of each sampled SLR scenario with its corresponding probability.

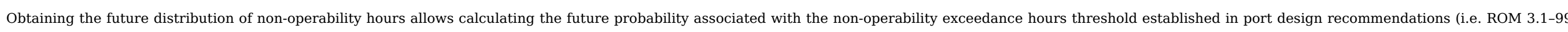

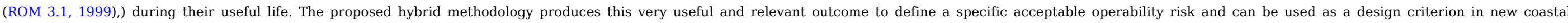
infrastructure or for climate change adaptation plans.

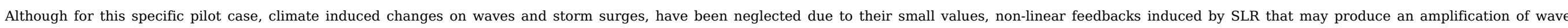

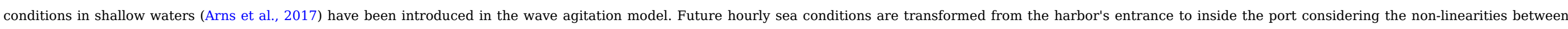
tides, surges, waves and SLR. Changes in the reflection coefficient inside the port due to changes in sea level have also been implemented in the wave agitation simulation.

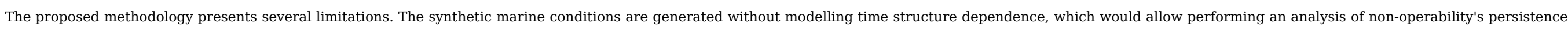

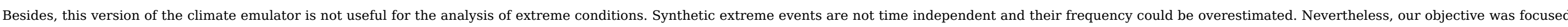
on port operability which should not be conditioned by extreme events.

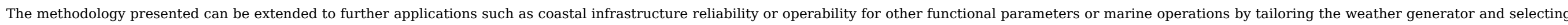
the most appropriate numerical model.

\section{Acknowledgments}

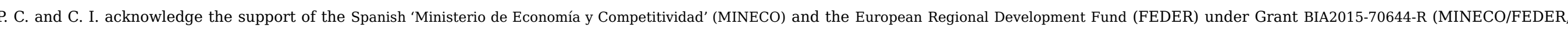
$\mathrm{UE})$.

\section{Appendix A. Supplementary data}

Supplementary data to this article can be found online at https://doi.org/10.1016/j.coastaleng.2019.01.007.

\section{References}

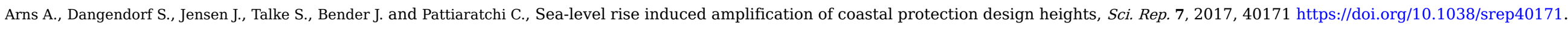


Bamber J.L. and Aspinall W.P., An expert judgement assessment of future sea level rise from the ice sheets, Nat. Clim. Change 3, 2013, 424-427, https://doi.org/10.1038/nclimate1778.

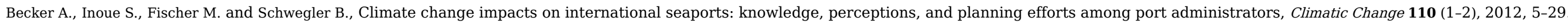

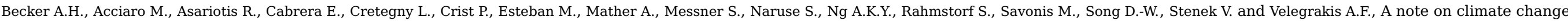
adaptation for seaports: a challenge for global ports, a challenge for global society, Climatic Change 120 (4), 2013, 683-695.

Camus P., Mendez F.J. and Medina R., A hybrid efficient method to downscale wave climate to coastal areas, Coast Eng. 58 (9), $2011,851-862$.

Camus P., Méndez F.J., Medina R., Tomás A. and Izaguirre C., High resolution downscaled ocean waves (DOW) reanalysis in coastal areas, Coast Eng. 72, 2013 , 56-68.

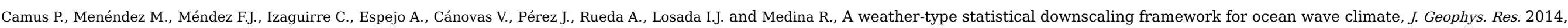
https://doi.org/10.1002/2014JC010141.

Camus P., Losada I.J., Izaguirre C., Espejo A., Menéndez M. and Pérez J., Statistical wave climate projections for coastal impact assessments, Earth's Future 5 (9), 2017 , 918-933.

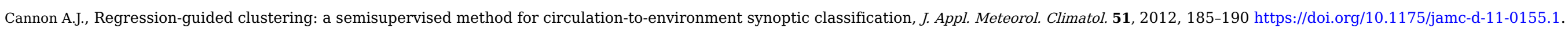

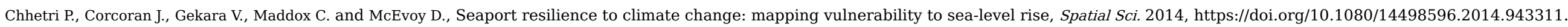

Cid A., Castanedo S., Abascal A.J., Menéndez M. and Medina R., A high resolution hindcast of the meteorological sea level component for Southern Europe: the GOS dataset, Clim. Dynam. 2014,

https://doi.org/10.1007/s00382-013-2041-0.

Corbella S. and Stretch D.D., Simulating a multivariate sea storm using Archimedean copulas, Coast Eng. 76, 2013, 68-78.

Diaz-Hernandez G., Mendez F.J., Losada I.J., Camus P. and Medina R., A nearshore long-term infragravity wave analysis for open harbours, Coast Eng. 97, 2015, 78-90.

GIOC, MSP: A Finite Element Model for Wave Agitation in Ports. Technical Report and User Manual, 2000, Universidad de Cantabria, (in Spanish).

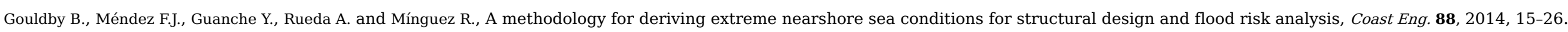

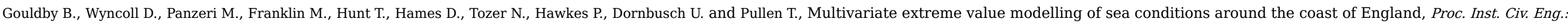
Maritime Eng. 170 (1), 2017, 3-20.

Guedes Soares C. and Cunha C., Bivariate autoregressive models for the time series of significant wave height and mean period, Coast Eng. 40, 2000, 297-311.

Heffernan J.E. and Tawn J.A., A conditional approach for multivariate extreme values (with discussion), J. Roy. Stat. Soc. 66 (3), $2004,497-546$.

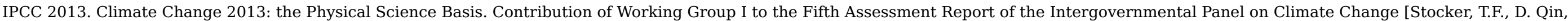

G.-K. Plattner, M. Tignor, S.K. Allen, J. Boschung, A. Nauels, Y. Xia, V. Bex and P.M. Midgley (eds.)].

López I., López M. and Iglesias G., Artificial neural networks applied to port operability assessment, Ocean Eng. 109, 2015, $298-308$.

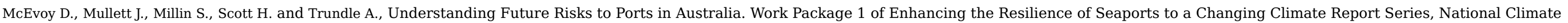

Change Adaptation Research Facility, Gold Coast, 2013, 77.

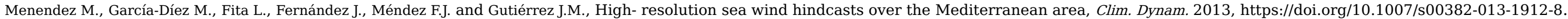

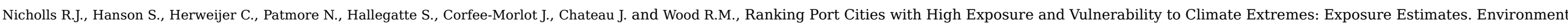

Working Papers no.1, 2008, OECD.

Perez J., Menendez M., Camus P., Mendez F.J. and Losada I.J., Statistical multi-model climate projections of surface ocean waves in Europe, Ocean Model. 96, 2015, 161-170. 


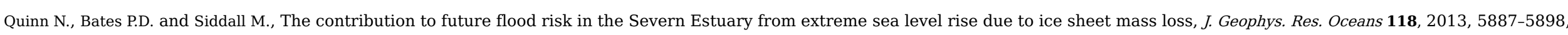

https://doi.org/10.1002/jgrc.20412.

Ranasinghe R., Assessing climate change impacts on open sandy coasts: a review, Earth Sci. Rev. 160, 2016, 320-332.

Reguero B.G., Menéndez M., Méndez F.J., Mínguez R. and Losada I.J., A Global Ocean Wave (GOW) Calibrated Reanalysis from 1948 Onwards Coastal Engineering vol. 65, $2012,38-55$.

Rippa S., An algorithm for selecting a good value for the parameter c in radial basis function interpolation, Adv. Comp. Math. 11, 1999, 193-210.

ROM 0.0, General Procedure \& Requirements for Design of Maritime \& Harbour Structures (Part I); Puertos del Estado, 2001, ISBN: 84-88975-31-7. www.puertos.es.

ROM 3.1, Maritime Port Configuration Design: Approach channel \& Harbour basin; Puertos del Estado, 1999, ISBN: 84-88975-52-X. www.puertos.es.

Rueda A., Camus P., Tomás A., Vitousek S. and Méndez F.J., A multivariate extreme wave and storm surge climate emulator based on weather patterns, Ocean Model. 104, 2016, 242-251.

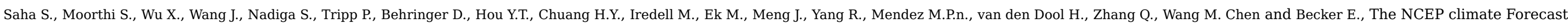
system version 2, J. Clim. 27, 2014, 2185-2208, https://doi.org/10.1175/JCLI-D-12-00823.1.

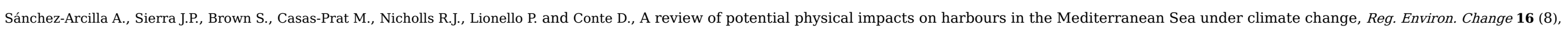
2016, 2471-2484.

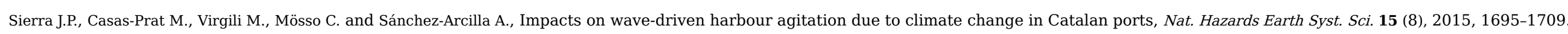

Sierra J.P., Genius A., Lionello P., Mestres M., Mösso C. and Marzo L., Modelling the impact of climate change on harbour operability: the Barcelona port case study, Ocean Eng. 141, 2017 , 64-78.

Slangen A.B.A., Carson M. and Katsman C.A., Modelling twenty-first century regional sea-level changes, Climatic Change 2014, https://doi.org/10.1007/s10584-014-1080-9.

Solari S. and Losada M.A., Unified distribution models for met-ocean variables: application to series of significant wave height, Coast Eng. 68, $2012 \underline{a}, 67-77$.

Solari S. and Losada M.T., Simulation of non-stationary wind speed and direction time series, J. Wind Eng. Ind. Aerod. 149, 2016, 48-58.

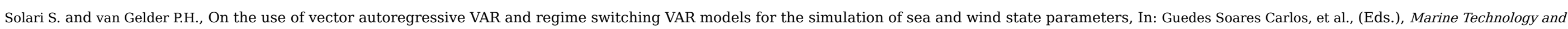

Engineering, 2012 $\underline{b}$, Taylor \& Francis Group; London, 217-230.

Toimil A., Losada I.J., Camus P. and Díaz-Simal P., Managing coastal erosion under climate change at the regional scale, Coast Eng. 128, $2017,106-122$.

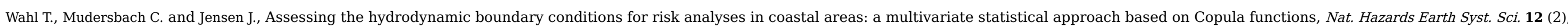
$2012,495-510$.

Wahl T., Plant N.G. and Long J.W., Probabilistic assessment of erosion and flooding risk in the northern Gulf of Mexico, J. Geophys. Res. Oceans 121, 2016, https://doi.org/10.1002/2015JC011482.

\section{Appendix A. Supplementary data}

The following is the supplementary data to this article:

Multimedia Component 1

Data Profile

alt-text: Data Profile 
Highlights

- Probabilistic evaluation of climate change impacts on port operations taking into account the uncertainty due to SLR projections.

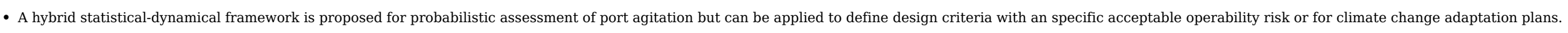

- The framework combines a weather generator to introduce the uncertainty of multivariate marine forcing conditions and a metamodel for an efficient numerical modelling.

\section{Queries and Answers}

Query: Highlights should only consist of "125" characters per bullet point, including spaces. The highlights provided are too long; please edit them to meet the requirement.

Answer: - Probabilistic evaluation of climate change impacts on port operations including the uncertainty due to SLR projections.

- The proposed hybrid framework combines a weather generator and a metamodel for an efficient physical-process modelling

- The framework can be applied to define design criteria with an specific acceptable operability risk.

- The framework can be used for climate change adaptation plans.

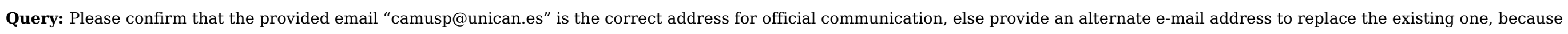
private e-mail addresses should not be used in articles as the address for communication.

Answer: Yes, it is correct

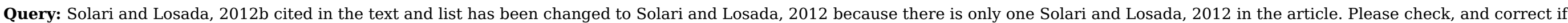
necessary.

Answer: Ok, it is correct as you propose. There are two references of Solari in 2012 but with different co-autor. Solari S. and Losada M.A, 2012

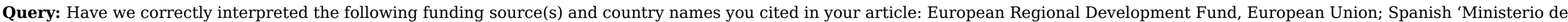
Economía y Competitividad' (MINECO)?

Answer: Yes

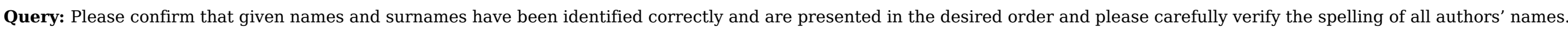

Answer: Yes

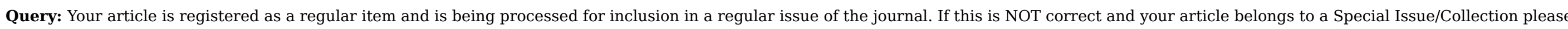
contact s.natarajan.2@elsevier.com immediately prior to returning your corrections.

Answer: Yes 